\title{
Effect of salt additives on partition of nonionic solutes in aqueous PEG-sodium sulfate two-phase system
}

\author{
Luisa A. Ferreira ${ }^{a}$, Jose A. Teixeira ${ }^{a}$, Larissa M. Mikheeva ${ }^{b}$, Arnon Chait $^{b}$, Boris Y. Zaslavsky ${ }^{b, *}$ \\ a IBB - Institute for Biotechnology and Bioengineering, Centre of Biological Engineering, Universidade do Minho, Campus de Gualtar, 4710-057 Braga, Portugal \\ ${ }^{\mathrm{b}}$ Analiza, Inc., 3615 Superior Ave., Cleveland, OH 44114, USA
}

\section{A R T I C L E I N F O}

\section{Article history:}

Received 21 January 2011

Received in revised form 18 May 2011

Accepted 19 May 2011

Available online 27 May 2011

\section{Keywords:}

Aqueous two-phase systems

Salt additives

Non-ionic solutes partitioning

Collander equation

\begin{abstract}
A B S T R A C T
Partition of 12 nonionic organic compounds in aqueous PEG-8000- $\mathrm{Na}_{2} \mathrm{SO}_{4}$ two-phase system was examined. Effects of four salt additives $\left(\mathrm{NaCl}, \mathrm{NaSCN}, \mathrm{NaClO}_{4}\right.$, and $\left.\mathrm{NaH}_{2} \mathrm{PO}_{4}\right)$ in the concentration range from 0.027 up to ca. $1.9 \mathrm{M}$ on binodal curve of PEG-sulfate two-phase system and solute partitioning were explored. It was found that different salt additives at the relatively high concentrations display different effects on both phase separation and partition of various nonionic solutes. Analysis of the results indicates that the PEG- $\mathrm{Na}_{2} \mathrm{SO}_{4}$ ATPS with the up to $0.215 \mathrm{M} \mathrm{NaCl}$ concentration may be viewed as similar to the ATPS without $\mathrm{NaCl}$ in terms of the Collander equation's predictive ability of the partitioning behavior of nonionic compounds. All ATPS with each of the salt additive used at the concentration of $0.027 \mathrm{M}$ may be viewed as similar to each other as the Collander equation holds for partition coefficients of nonionic solutes in these ATPS. Collander equation is valid also for the compounds examined in the ATPS with additives of $\mathrm{NaSCN}$ and $\mathrm{NaClO}_{4}$ at the concentrations up to $0.215 \mathrm{M}$. The observed similarity between these ATPS might be explained by the similar effects of these two salts on the water structure. At concentrations of the salt additives exceeding the aforementioned values, different effects of salt additives on partitioning of various nonionic solutes are displayed. In order to explain these effects of salt additives it is necessary to examine the intensities of different solute-solvent interactions in these ATPS within the framework of the so-called Linear Solvation Energy Relationship (LSER) model.
\end{abstract}

(C) 2011 Elsevier B.V. All rights reserved.

\section{Introduction}

Aqueous two-phase systems (ATPS) are formed by the addition of two (or more) water-soluble polymers or a single polymer and specific salt to an aqueous solution above certain critical concentrations or temperature. As a result, two immiscible aqueous phases are formed. Solutes as varied in size as inorganic ions, small organic molecules, and biological macromolecules as well as particles from colloidal inorganic particles, viruses, and cells may be partitioned between the phases of ATPS.

ATPS formed by polyethylene glycol (PEG) and inorganic salt, such as sodium sulfate or phosphate, are commonly used for protein purification due to their low cost and good operational characteristics [1-4]. Extraction in ATPS has been demonstrated as an efficient method for large scale recovery and purification of biological products $[1,3,4]$. Low cost, high capacity, and easy scale-up are clear advantages of this technology. For successful utilization of partitioning in ATPS it is important to understand the mechanisms

\footnotetext{
* Corresponding author. Tel.: +1 216432 9050x1-11; fax: +1 2164329050

E-mail address: bz@analiza.com (B.Y.Zaslavsky).
}

of solute distribution in the systems as well as system properties at the molecular level.

It is well established that the solute partitioning in two-polymer and polymer-salt ATPS is affected by similar factors. Salt additives are among the factors which are known to strongly influence the solute partitioning in two-polymer ATPS [5]. It is also known that salt additives may affect protein partitioning in polymer-salt ATPS [2-4]. The most widely used salt additive in these ATPS is $\mathrm{NaCl}$. The choice of $\mathrm{NaCl}$ as an additive affecting protein partitioning is likely to be due to $\mathrm{NaCl}$ commonly viewed as being relatively neutral to proteins. $\mathrm{NaCl}$ is generally used in the concentration range up to 15 wt.\%, i.e. up to ca. $2.6 \mathrm{M}$ [2-4,6-11]. The effects of several other salt additives, such as perchlorate and different chlorides, on protein partitioning in PEG-salt ATPS were also reported [12-15]. The only study of the effects of $\mathrm{NaCl}, \mathrm{NaBr}$, and $\mathrm{NaI}$ additives on the phase diagram of PEG/potassium phosphate to our knowledge is reported by Bertoluzzo et al. [12]. It was shown [12] that at the concentration of $0.3 \mathrm{M}$ these salt additives did change the position of binodal curve observed for the ATPS without salt additive. The mechanisms underlying the effects of salt additives on the solute partitioning in PEG-salt ATPS was never systematically studied, especially in the case where the salt additive is present in an ATPS on the background of large excess of the phase-forming salt. For 
some proteins the effects in question may be assigned to specific ion-protein interactions but this explanation does not fully cover the effects observed for a variety of proteins.

It is clear that mechanism of solute partitioning in ATPS is difficult to explore using such structurally complex solutes as proteins. It is much easier to gain better insight into the mechanism of solute partitioning using simple small organic compounds. We used such compounds in this work to explore the effects of four different salt additives $\left(\mathrm{NaCl}, \mathrm{NaSCN}, \mathrm{NaClO}_{4}\right.$ and $\left.\mathrm{NaH}_{2} \mathrm{PO}_{4}\right)$ on partitioning of simple nonionic organic compounds in the PEG-sodium sulfate ATPS.

\section{Experimental}

\subsection{Materials}

Polyethylene glycol-8000 (Lot 048K00241) with an average molecular weight $\left(M_{\mathrm{W}}\right)$ of 8000 was purchased from Sigma-Aldrich (St. Louis, MO, USA). Caffeine; 4nitrophenyl- $\alpha$-D-glucopyranoside, 3-hydroxybenzaldehyde; 1,3,5-trihydroxybenzene; 4-hydroxyacetanilide; adenosine; guanosine; D-(-)-salicin; and 4-aminophenol were purchased from Sigma-Aldrich. 4-Nitrophenyl- $\alpha$-D-mannopyranoside was obtained from USB Corporation (Cleveland, OH, USA); 4nitroanisole was supplied by Acros Organics (Geel, Belgium) and phenol was provided by MB Biomedicals (Solon, OH, USA). All compounds were of 98-99\% purity and used as received without further purification.

All inorganic salts were of analytical reagent grade and used without further purification. Sodium sulfate anhydrous, sodium chloride, and sodium phosphate monobasic monohydrate were purchased from USB Corporation. Sodium phosphate dibasic heptahydrate was obtained from EMD Chemicals (Gibbstown, NJ, USA), sodium thiocyanate was supplied by Sigma-Aldrich and sodium perchlorate was purchased from Fisher Scientific (Pittsburgh, PA, USA).

\subsection{Methods}

\subsubsection{Aqueous two-phase systems}

Stock solutions of PEG 8000 (50wt.\%) and $\mathrm{Na}_{2} \mathrm{SO}_{4}$ (20.3 wt.\%) were prepared in water. Sodium phosphate buffer (NaPB; $0.5 \mathrm{M}$, $\mathrm{pH} 6.8$ ) was prepared by mixing $3.45 \mathrm{~g}$ of $\mathrm{NaH}_{2} \mathrm{PO}_{4} \cdot \mathrm{H}_{2} \mathrm{O}$ and $6.70 \mathrm{~g}$ $\mathrm{Na}_{2} \mathrm{HPO}_{4} \cdot 7 \mathrm{H}_{2} \mathrm{O}$ in $100 \mathrm{ml}$ aqueous solution.

A mixture of PEG and salts was prepared by dispensing appropriate amounts of the aqueous stock PEG-8000, $\mathrm{Na}_{2} \mathrm{SO}_{4}$ and $\mathrm{NaPB}$ solutions into a $1.2 \mathrm{ml}$ microtube using a Hamilton (Reno, NV, USA) ML-4000 four-probe liquid handling workstation. Appropriate amounts of water and/or stock salt additives solutions were added to give the required ionic and polymer composition of the final system with total weight of $0.5 \mathrm{~g}$ (after addition of the solute sample, see below). All aqueous two-phase systems had a fixed composition of 11.10 wt.\% PEG-8000, 6.33 wt.\% $\mathrm{Na}_{2} \mathrm{SO}_{4}$ and $0.01 \mathrm{M}$ $\mathrm{NaPB}, \mathrm{pH}$ 6.8, with different salt additive concentrations as indicated below. Stock solutions of each salt additive $\left(\mathrm{NaCl}, \mathrm{NaClO}_{4}\right.$, $\mathrm{NaSCN}$ or $\mathrm{NaH}_{2} \mathrm{PO}_{4}$ ) of 0.5 or $5.0 \mathrm{M}$ concentration were prepared and appropriated amounts were added to the two-phase systems to provide the required concentrations from $0.027 \mathrm{M}$ up to ca. $1.9 \mathrm{M}$.

In separate experiments, blank systems of the same composition but of $4 \mathrm{~g}$ total weights have been prepared in order to measure accurately the volumes of both phases. After vigorous mixing the systems were centrifuged for $60 \mathrm{~min}$ at $3000 \times \mathrm{g}$ at $23^{\circ} \mathrm{C}$ temperature in a refrigerated centrifuge (Jouan, BR4i, Thermo Fisher Scientific, Waltham, MA, USA) to accelerate phase settling. Following phase separation the volume of each phase was marked in each tube and the respective volumes were calculated from the mass of water which occupied the same volume as the corresponding phase. Each experiment for a given composition of the system was performed in triplicate and the average volumes of the phases were calculated. The relative error of the phase volume did not exceed $2 \%$ in each case.

Phase diagrams were determined by the turbidimetric titration method [16] as described previously [17] and fitted by least squares regression to an empirical relationship developed by Merchuk et al. [18] and shown in Eq. (1):

$Y=a \times \exp \left(b \times X^{0.5}-c \times X^{3}\right)$

where $Y$ and $X$ are the polymer and salt concentrations in mass fraction, respectively, and $a, b$, and $c$ are adjustable parameters without any clear physical meaning.

\subsubsection{Partitioning experiments}

The aqueous two-phase partitioning experiments were performed using an automated instrument, Automated Signature Workstation, ASW (Analiza, Cleveland, OH, USA). The ASW system is based on the ML-4000 liquid-handling workstation (Hamilton Company) integrated with a UV-VIS microplate spectrophotometer (SpectraMax Plus384, Molecular Devices, Sunnyvale, CA, USA).

Solutions of all compounds were prepared in water at concentrations of $2-100 \mathrm{mM}$, depending on the compound solubility. Varied amounts $(0,20,40,60,80$, and $100 \mu \mathrm{l})$ of a given compound solution and the corresponding amounts $(100,80,60,40,20$, and $0 \mu \mathrm{l}$ ) of water were added to a set of the same polymer/salts mixtures. The systems were vortexed in a multi-pulse vortexer and centrifuged for $60 \mathrm{~min}$ at $3000 \times g$ at $23^{\circ} \mathrm{C}$ temperature in a refrigerated centrifuge (Jouan, BR4i) to accelerate phase settling. The upper phase in each system was partially removed, the interface discarded, and aliquots of 15-75 $\mu$ l from the upper and lower phases were withdrawn in duplicate for analysis. The aliquots were transferred into microplate wells and diluted up to $300 \mu \mathrm{l}$. In the cases of considerable difference between the concentrations of a given compound in one phase relative to the other phase, different dilution factors were used for the upper and lower phases. Water was used as a diluent for all but four compounds (phenol; hydroxybenzaldehyde; trihydroxybenzene; hydroxyacetanilide). $20 \mathrm{mM}$ universal buffer (NaUB) with $\mathrm{pH} 12.4$ was used as a diluent for these compounds. The microplate was sealed, and following moderate shaking for $30 \mathrm{~min}$ in an incubator (Vortemp 56EVC, Labnet International, Edison, NJ, USA) at room temperature and short centrifugation ( $3 \mathrm{~min}$ at $1500 \mathrm{rpm}$ ), optical absorbance was measured at the wavelength of maximum absorption with the UV-VIS plate reader. The maximum absorption wavelength for each compound was determined in separate experiments by analysis of the absorption spectrum over the $250-500 \mathrm{~nm}$ range. In the case of the four aforementioned compounds the maximum absorption was found to be more concentration sensitive in the presence of the universal buffer (NaUB) at pH 12.4. In all measurements the correspondingly diluted pure phases were used as blank solutions.

The partition coefficient, $K$, defined as the ratio of the sample concentration in the upper phase to the sample concentration in the lower phase was determined as the slope of the compound concentration in the upper phase plotted as a function of the concentration in the lower phase averaged over the results obtained from two to four partition experiments carried out at the specified polymer and salt composition of the system, taking into consideration the corresponding dilution factors used in the experiment [5]. Deviation from the average $K$-value was consistently below $5 \%$ and in most cases lower than $2 \%$. 


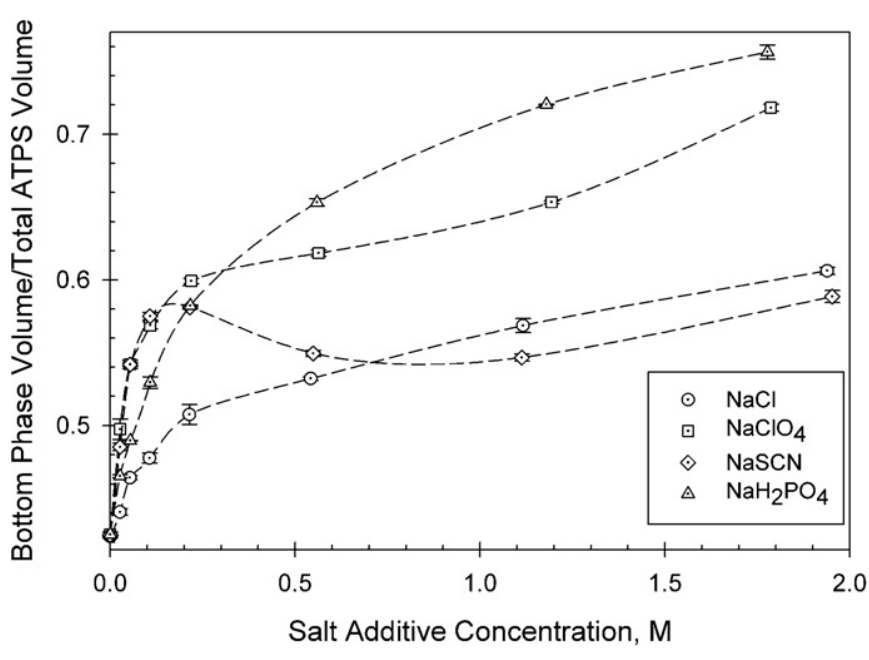

Fig. 1. Concentration effects of salt additives on the ratio of the volume of bottom phase to the total volume of aqueous PEG-8000- $\mathrm{Na}_{2} \mathrm{SO}_{4}$ two-phase system. Lines connecting the experimental points are added for eye-guidance only.

\section{Results}

The specific choice of the PEG/salt composition of the ATPS used in this work was made to enable the examination of the highest possible concentrations of salt additives, limited by their solubility. The binodal curve for the PEG- $\mathrm{Na}_{2} \mathrm{SO}_{4}$ ATPS used here agrees well with the literature data $[17,19,20]$ and shows essentially no effect of $0.01 \mathrm{M} \mathrm{NaPB}, \mathrm{pH} 6.8$ on phase separation in PEG-8000/ $\mathrm{Na}_{2} \mathrm{SO}_{4}$ mixture in water. It should be noted that the "salt additive" term should be viewed rather loosely, especially in the range of the salt concentrations exceeding that of the $\mathrm{Na}_{2} \mathrm{SO}_{4}(\sim 0.5 \mathrm{M})$.

The ratio of the volumes of the phases varies with the concentration of a salt additive in a salt-specific manner as shown in Fig. 1 (lines connecting the experimental points are added for eyeguidance only). It should be mentioned that the total volume of the $\mathrm{PEG}-\mathrm{Na}_{2} \mathrm{SO}_{4}$ ATPS of the fixed polymer and sulfate concentrations gradually decreased with increased salt additive concentration proportionally to the density of the salt additive solution (data not shown). The data presented in Fig. 1 appear rather unexpected. The observed gradual changes in the phase volumes ratios in the presence of increasing amounts of $\mathrm{NaCl}, \mathrm{NaClO}_{4}$ and $\mathrm{NaH}_{2} \mathrm{PO}_{4}$ additives might be related to gradual changes of the position and shape of the original ATPS binodal curve as shown in Figs. 2-5.

The effect of $\mathrm{NaCl}$ additive appears to be very small at the concentrations below $0.1 \mathrm{M}$ and is more noticeable in the $0.107-1.94 \mathrm{M}$ $\mathrm{NaCl}$ range. The two-phase region increases with the increasing $\mathrm{NaCl}$ concentration (Fig. 2). Similar but more pronounced concentration effects of $\mathrm{NaClO}_{4}$ and $\mathrm{NaH}_{2} \mathrm{PO}_{4}$ additives on phase separation are clearly seen in Figs. 3 and 5. Addition of $\mathrm{NaClO}_{4}$ and $\mathrm{NaH}_{2} \mathrm{PO}_{4}$ results in noticeable increase of the two-phase region and changes in the shape of the binodal curve both much more pronounced than in the case of $\mathrm{NaCl}$ additive. The observed effects of $\mathrm{NaClO}_{4}$ and $\mathrm{NaH}_{2} \mathrm{PO}_{4}$ on the position of the binodal curve appear to agree with that both these salts additives are likely to concentrate predominantly in the sulfate-rich phase due to their incompatibility with PEG-8000. The effects of different concentrations of NaSCN additive on the binodal curve (Fig. 4) are different. The shift down of the binodal curve is small up to $0.053 \mathrm{M} \mathrm{NaSCN}$ (similar to $\mathrm{NaCl}$ effects), increases at $0.107 \mathrm{M}$ and $0.215 \mathrm{M} \mathrm{NaSCN}$, and stays essentially in same place while slightly changing the shape at 0.543-1.936 M NaSCN. The observed NaSCN concentration effects on the binodal curve may possibly explain complicated concentration dependence of the phases volumes ratios in the presence of increasing amounts of $\mathrm{NaSCN}$ relative to those of $\mathrm{NaCl}, \mathrm{NaClO}_{4}$,

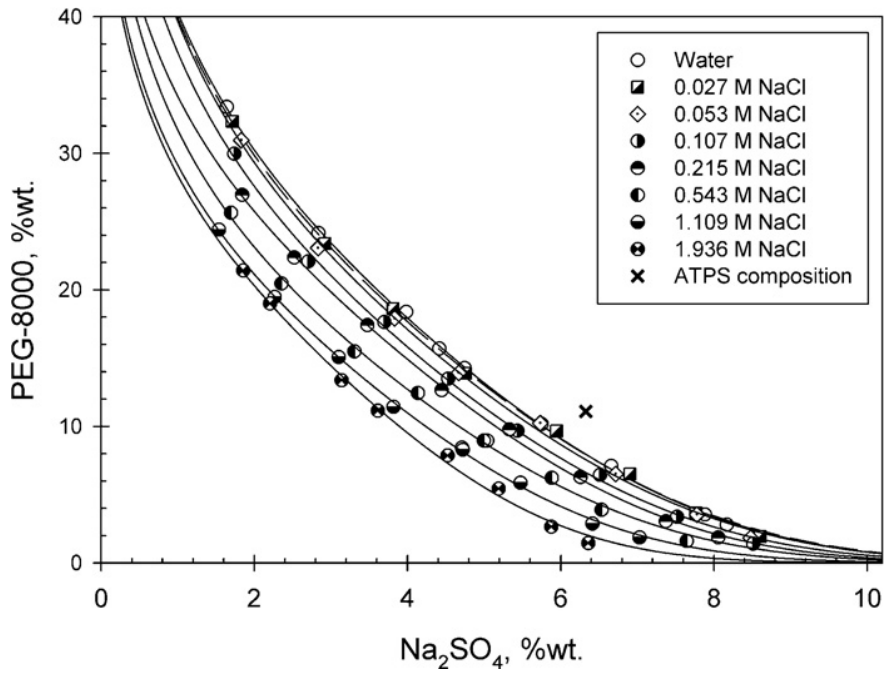

Fig. 2. Concentration effects of $\mathrm{NaCl}$ additive on the binodal curve of aqueous PEG$8000-\mathrm{Na}_{2} \mathrm{SO}_{4}$ two-phase system.

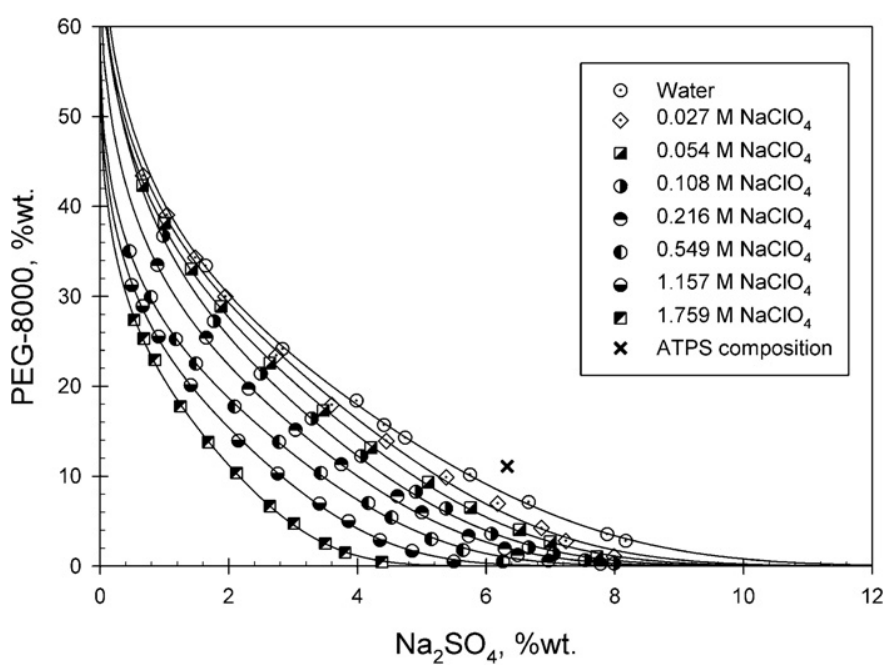

Fig. 3. Concentration effects of $\mathrm{NaClO}_{4}$ additive on the binodal curve of aqueous PEG-8000- $\mathrm{Na}_{2} \mathrm{SO}_{4}$ two-phase system.

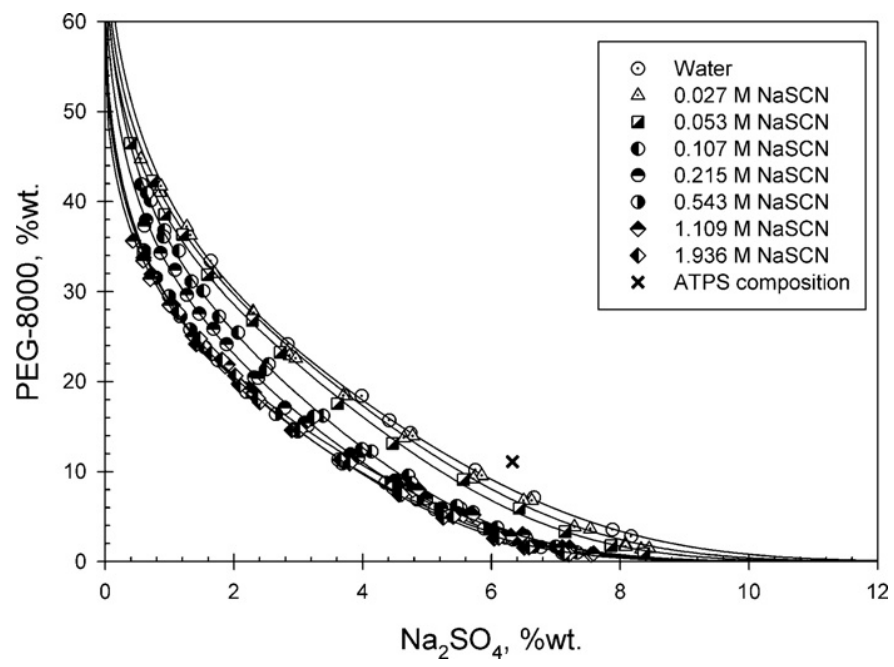

Fig. 4. Concentration effects of NaSCN additive on the binodal curve of aqueous PEG-8000- $\mathrm{Na}_{2} \mathrm{SO}_{4}$ two-phase system. 


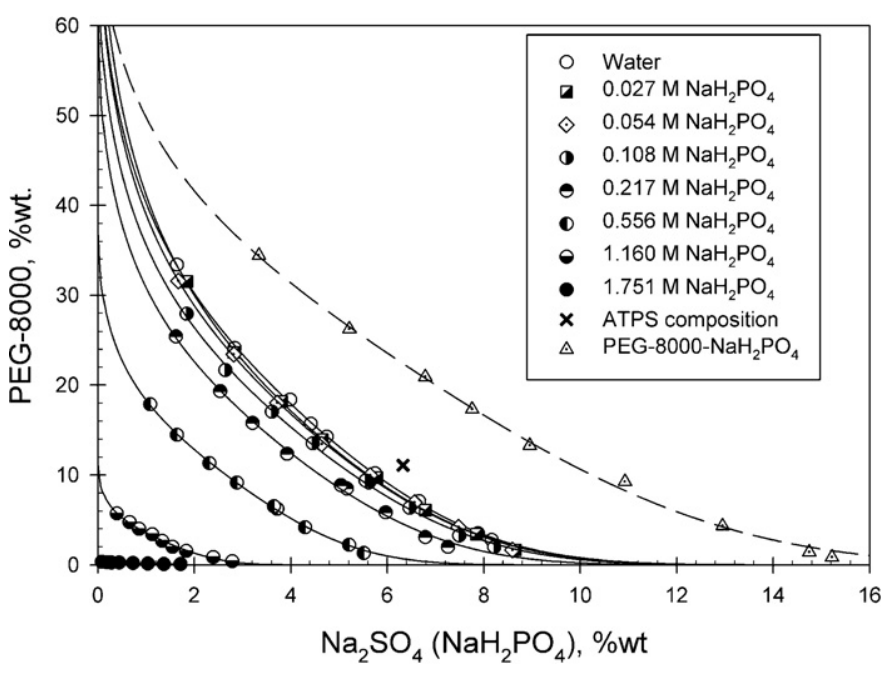

Fig. 5. Concentration effects of $\mathrm{NaH}_{2} \mathrm{PO}_{4}$ additive on the binodal curve of aqueous PEG-8000- $\mathrm{Na}_{2} \mathrm{SO}_{4}$ two-phase system.

and $\mathrm{NaH}_{2} \mathrm{PO}_{4}$ additives. It should also be mentioned that PEG and $\mathrm{NaClO}_{4}$ may form aqueous two-phase system without $\mathrm{Na}_{2} \mathrm{SO}_{4}$ though at much higher $\mathrm{NaClO}_{4}$ concentrations than used here. This observation remains to be explored further.

The partition coefficients of all the nonionic solutes examined in PEG- $\mathrm{Na}_{2} \mathrm{SO}_{4}$ ATPS at different concentrations of $\mathrm{NaCl}$ additive are listed in Table 1. These data are plotted in Fig. 6 and they demonstrate that the $\mathrm{NaCl}$ additive affect partitioning of all the compounds examined in a similar manner. An increase in the $\mathrm{NaCl}$ concentration results in increased partition coefficient of a nonionic solute in the ATPS under study.

Partition coefficient values observed for the same solutes in the ATPS at different concentrations of $\mathrm{NaClO}_{4}$ are listed in Table 2 and plotted in Fig. 7. It should be noticed that the concentration effects of this salt additive on the partitioning of caffeine, adenosine, and

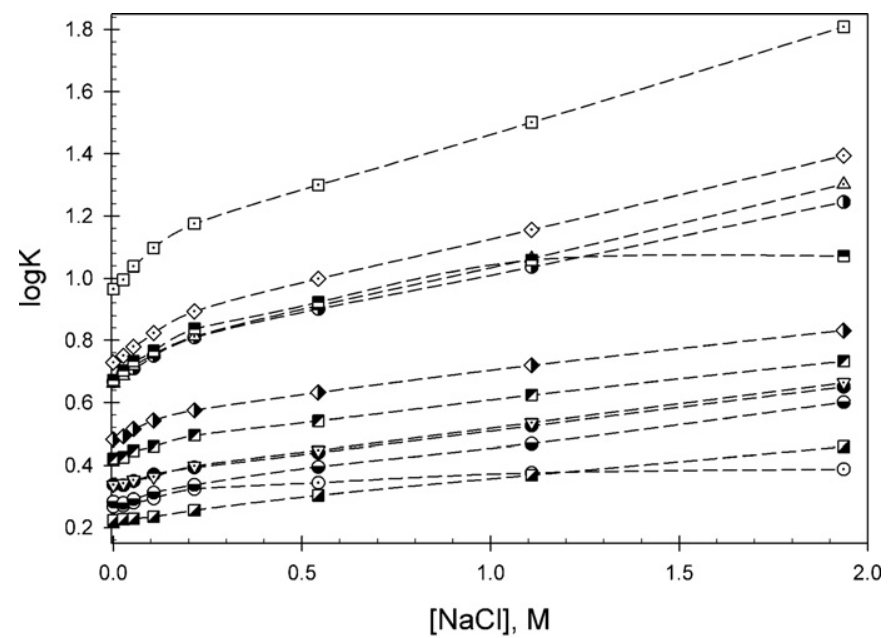

\begin{tabular}{|llll|}
\hline$\bullet$ pNP- $\alpha$-D-Glucopyranoside & $\odot$ & 4-Hydroxyacetanilide \\
$\odot$ Caffein & $\mathbf{v}$ & Adenosine \\
$\bullet$ & 3-Hydroxybenzaldehyde & $\bullet$ & Salicin \\
$\Delta$ & Phenol & $\bullet$ & p-Nitroanisole \\
$\nabla$ & pNP- $\alpha$-D-Mannopyranoside & $\square$ & Guanosine \\
$\square$ & Trihydroxybenzene & $\diamond$ & p-Aminophenol \\
\hline
\end{tabular}

Fig. 6. Concentration effects of $\mathrm{NaCl}$ additive on the logarithms of partition coefficients of nonionic compounds in aqueous PEG-8000- $\mathrm{Na}_{2} \mathrm{SO}_{4}$ two-phase system. Lines connecting the experimental points are added for eye-guidance only.

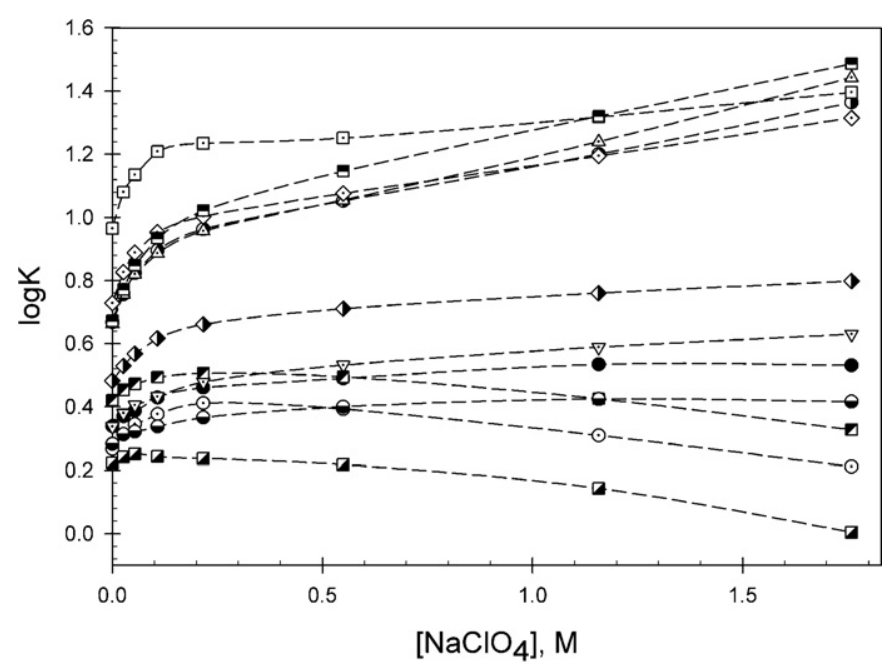

\begin{tabular}{|c|c|c|c|}
\hline$\bullet$ & pNP- $\alpha$-D-Glucopyranoside & $\diamond$ & 4-Hydroxyacetanilide \\
\hline$\odot$ & Caffein & $\boldsymbol{\nabla}$ & Adenosine \\
\hline - & 3-Hydroxybenzaldehyde & $\ominus$ & Salicin \\
\hline$\Delta$ & Phenol & $\mathbf{\Xi}$ & p-Nitroanisole \\
\hline$\nabla$ & pNP- $\alpha-D-M a n n o p y r a n o s i d e$ & a & Guanosine \\
\hline ๑ & Trihydroxybenzene & $\triangleleft$ & p-Aminophenol \\
\hline
\end{tabular}

Fig. 7. Concentration effects of $\mathrm{NaClO}_{4}$ additive on the logarithms of partition coefficients of nonionic compounds in aqueous PEG-8000- $\mathrm{Na}_{2} \mathrm{SO}_{4}$ two-phase system. Lines connecting the experimental points are added for eye-guidance only.

guanosine are clearly different from those on the partitioning of the other solutes.

The effect of the NaSCN additive on the partitioning of various nonionic solutes in the ATPS (Table 3 ) is even more pronounced, as shown in Fig. 8.

The concentration effects of the $\mathrm{NaH}_{2} \mathrm{PO}_{4}$ additive on the partitioning of the solutes examined (Table 4), as shown in Fig. 9, are not as pronounced as those corresponding to NaSCN but noted changes were nevertheless observed in some cases, e.g. adenosine and guanosine. Trihydroxybenzene and p-aminophenol were

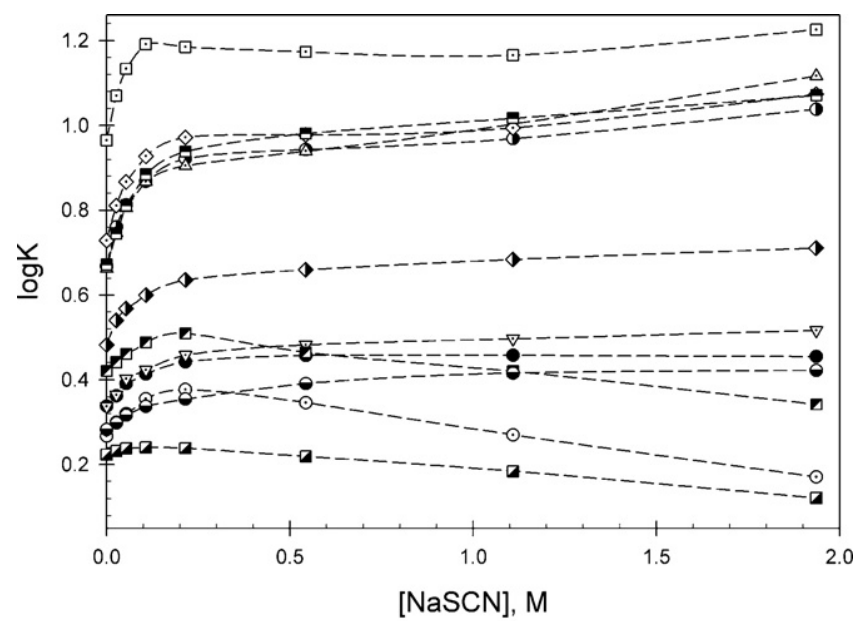

\begin{tabular}{|c|c|c|c|}
\hline$\bullet$ & pNP- $\alpha$-D-Glucopyranoside & $\diamond$ & 4-Hydroxyacetanilide \\
\hline$\odot$ & Caffein & ע & Adenosine \\
\hline - & 3-Hydroxybenzaldehyde & $\boldsymbol{\theta}$ & Salicin \\
\hline$\Delta$ & Phenol & = & p-Nitroanisole \\
\hline$\nabla$ & pNP- $\alpha$-D-Mannopyranoside & a & Guanosine \\
\hline ๑ & Trihydroxybenzene & $\triangleleft$ & p-Aminophenol \\
\hline
\end{tabular}

Fig. 8. Concentration effects of NaSCN additive on the logarithms of partition coefficients of nonionic compounds in aqueous PEG-8000- $\mathrm{Na}_{2} \mathrm{SO}_{4}$ two-phase system. Lines connecting the experimental points are added for eye-guidance only. 
Table 1

Partition coefficients of nonionic compounds in PEG-8000- $\mathrm{Na}_{2} \mathrm{SO}_{4}$ aqueous two-phase system with different concentrations of NaCl additive.

\begin{tabular}{|c|c|c|c|c|c|c|}
\hline $\mathrm{NaCl}(\mathrm{M})$ & Glucoside $^{\mathrm{a}}$ & Caffeine & 3-Hydroxybenzaldehyde & Phenol & Mannoside $^{\mathrm{b}}$ & Trihydroxybenzene \\
\hline 0 & $2.179 \pm 0.023$ & $1.850 \pm 0.039$ & $4.7 \pm 0.12$ & $4.598 \pm 0.084$ & $2.174 \pm 0.017$ & $9.224 \pm 0.047$ \\
\hline 0.027 & $2.167 \pm 0.025$ & $1.864 \pm 0.024$ & $4.941 \pm 0.163$ & $4.857 \pm 0.067$ & $2.199 \pm 0.030$ & $9.9 \pm 0.21$ \\
\hline 0.053 & $2.236 \pm 0.033$ & $1.905 \pm 0.028$ & $5.123 \pm 0.091$ & $5.229 \pm 0.098$ & $2.252 \pm 0.028$ & $10.9 \pm 0.24$ \\
\hline 0.107 & $2.348 \pm 0.030$ & $1.969 \pm 0.049$ & $5.630 \pm 0.195$ & $5.701 \pm 0.075$ & $2.309 \pm 0.031$ & $12.5 \pm 0.34$ \\
\hline 0.215 & $2.471 \pm 0.033$ & $2.107 \pm 0.036$ & $6.445 \pm 0.106$ & $6.5 \pm 0.17$ & $2.499 \pm 0.038$ & $15 \pm 0.26$ \\
\hline 0.543 & $2.755 \pm 0.054$ & $2.209 \pm 0.025$ & $7.963 \pm 0.60$ & $8.2 \pm 0.15$ & $2.803 \pm 0.038$ & $19.9 \pm 0.31$ \\
\hline 1.109 & $3.355 \pm 0.062$ & $2.376 \pm 0.036$ & $10.859 \pm 0.300$ & $12 \pm 0.21$ & $3.432 \pm 0.055$ & $31.7 \pm 0.68$ \\
\hline 1.936 & $4.477 \pm 0.068$ & $2.438 \pm 0.043$ & $17.588 \pm 0.484$ & $20 \pm 0.42$ & $4.615 \pm 0.058$ & $64 \pm 3.4$ \\
\hline $\mathrm{NaCl}(\mathrm{M})$ & Adenosine & Salicin & p-Nitroanisole & Guanosine & 4-Aminophenol & 4-Hydroxyacetanilide \\
\hline 0 & $2.634 \pm 0.017$ & $1.918 \pm 0.070$ & $4.697 \pm 0.062$ & $1.673 \pm 0.008$ & $3.038 \pm 0.049$ & $5.353 \pm 0.045$ \\
\hline 0.027 & $2.661 \pm 0.041$ & $1.901 \pm 0.030$ & $5.035 \pm 0.099$ & $1.685 \pm 0.058$ & $3.106 \pm 0.043$ & $5.640 \pm 0.104$ \\
\hline 0.053 & $2.789 \pm 0.039$ & $1.954 \pm 0.026$ & $5.407 \pm 0.145$ & $1.694 \pm 0.039$ & $3.272 \pm 0.061$ & $6.031 \pm 0.109$ \\
\hline 0.107 & $2.879 \pm 0.051$ & $2.054 \pm 0.053$ & $5.838 \pm 0.124$ & $1.718 \pm 0.025$ & $3.490 \pm 0.071$ & $6.657 \pm 0.126$ \\
\hline 0.215 & $3.122 \pm 0.042$ & $2.174 \pm 0.043$ & $6.869 \pm 0.199$ & $1.802 \pm 0.028$ & $3.761 \pm 0.072$ & $7.820 \pm 0.098$ \\
\hline 0.543 & $3.479 \pm 0.042$ & $2.484 \pm 0.042$ & $8.366 \pm 0.211$ & $2.012 \pm 0.039$ & $4.291 \pm 0.071$ & $9.964 \pm 0.14$ \\
\hline 1.109 & $4.208 \pm 0.073$ & $2.944 \pm 0.051$ & $11.551 \pm 0.192$ & $2.335 \pm 0.061$ & $5.246 \pm 0.119$ & $14.31 \pm 0.29$ \\
\hline 1.936 & $5.41 \pm 0.104$ & $3.991 \pm 0.075$ & $17.840 \pm 1.041$ & $2.879 \pm 0.052$ & $6.797 \pm 0.144$ & $24.8 \pm 0.7$ \\
\hline
\end{tabular}

a p-Nitrophenyl- $\alpha$-D-glucopyranoside.

b p-Nitrophenyl- $\alpha$-D-mannopyranoside.

Table 2

Partition coefficients of nonionic compounds in PEG-8000- $\mathrm{Na}_{2} \mathrm{SO}_{4}$ aqueous two-phase system with different concentrations of NaClO 4 additive.

\begin{tabular}{|c|c|c|c|c|c|c|}
\hline $\mathrm{NaClO}_{4}(\mathrm{M})$ & Glucoside $\mathrm{a}^{\mathrm{a}}$ & Caffeine & 3-Hydroxybenzaldehyde & Phenol & Mannoside $^{\mathrm{b}}$ & Trihydroxybenzene \\
\hline 0 & $2.179 \pm 0.023$ & $1.850 \pm 0.039$ & $4.7 \pm 0.12$ & $4.598 \pm 0.084$ & $2.174 \pm 0.017$ & $9.224 \pm 0.047$ \\
\hline 0.027 & $2.347 \pm 0.026$ & $2.054 \pm 0.042$ & $5.7 \pm 0.14$ & $5.704 \pm 0.079$ & $2.400 \pm 0.053$ & $12.0 \pm 0.14$ \\
\hline 0.054 & $2.438 \pm 0.025$ & $2.213 \pm 0.048$ & $6.7 \pm 0.11$ & $6.610 \pm 0.057$ & $2.544 \pm 0.061$ & $13.6 \pm 0.16$ \\
\hline 0.108 & $2.690 \pm 0.052$ & $2.380 \pm 0.064$ & $7.9 \pm 0.13$ & $7.7 \pm 0.17$ & $2.706 \pm 0.057$ & $16.2 \pm 0.35$ \\
\hline 0.216 & $2.888 \pm 0.063$ & $2.578 \pm 0.040$ & $9.2 \pm 0.13$ & $9 \pm 0.23$ & $3.009 \pm 0.045$ & $17.2 \pm 0.39$ \\
\hline 0.549 & $3.092 \pm 0.045$ & $2.471 \pm 0.039$ & $11.3 \pm 0.11$ & $11 \pm 0.14$ & $3.406 \pm 0.044$ & $17.8 \pm 0.18$ \\
\hline 1.157 & $3.423 \pm 0.059$ & $2.040 \pm 0.036$ & $15.9 \pm 0.26$ & $17 \pm 0.58$ & $3.883 \pm 0.028$ & $20.8 \pm 0.29$ \\
\hline 1.759 & $3.400 \pm 0.061$ & $1.627 \pm 0.033$ & $23 \pm 1.2$ & $28 \pm 1.8$ & $4.267 \pm 0.052$ & $25 \pm 2.3$ \\
\hline $\mathrm{NaClO}_{4}(\mathrm{M})$ & Adenosine & Salicin & p-Nitroanisole & Guanosine & 4-Aminophenol & 4-Hydroxyacetanilide \\
\hline 0 & $2.634 \pm 0.017$ & $1.918 \pm 0.070$ & $4.697 \pm 0.062$ & $1.673 \pm 0.008$ & $3.038 \pm 0.049$ & $5.353 \pm 0.045$ \\
\hline 0.027 & $2.840 \pm 0.041$ & $2.058 \pm 0.041$ & $5.906 \pm 0.112$ & $1.742 \pm 0.021$ & $3.386 \pm 0.043$ & $6.706 \pm 0.120$ \\
\hline 0.054 & $2.969 \pm 0.044$ & $2.099 \pm 0.041$ & $7.044 \pm 0.177$ & $1.784 \pm 0.023$ & $3.705 \pm 0.048$ & $7.733 \pm 0.115$ \\
\hline 0.108 & $3.113 \pm 0.046$ & $2.178 \pm 0.040$ & $8.591 \pm 0.184$ & $1.750 \pm 0.023$ & $4.140 \pm 0.073$ & $8.969 \pm 0.137$ \\
\hline 0.216 & $3.208 \pm 0.059$ & $2.323 \pm 0.068$ & $10.501 \pm 0.194$ & $1.726 \pm 0.023$ & $4.584 \pm 0.049$ & $10.073 \pm 0.249$ \\
\hline 0.549 & $3.122 \pm 0.053$ & $2.514 \pm 0.048$ & $14.009 \pm 0.235$ & $1.650 \pm 0.024$ & $5.141 \pm 0.052$ & $11.913 \pm 0.284$ \\
\hline 1.157 & $2.662 \pm 0.054$ & $2.661 \pm 0.052$ & $20.908 \pm 0.496$ & $1.391 \pm 0.017$ & $5.759 \pm 0.088$ & $15.649 \pm 0.326$ \\
\hline 1.759 & $2.126 \pm 0.036$ & $2.607 \pm 0.044$ & $30.657 \pm 0.752$ & $1.011 \pm 0.018$ & $6.284 \pm 0.162$ & $20.671 \pm 0.759$ \\
\hline
\end{tabular}

a p-Nitrophenyl- $\alpha$-D-glucopyranoside.

b p-Nitrophenyl- $\alpha$-D-mannopyranoside.

Table 3

Partition coefficients of nonionic compounds in PEG-8000- $\mathrm{Na}_{2} \mathrm{SO}_{4}$ aqueous two-phase system with different concentrations of NaSCN additive.

\begin{tabular}{|c|c|c|c|c|c|c|}
\hline $\operatorname{NaSCN}(\mathrm{M})$ & Glucoside $^{\mathrm{a}}$ & Caffeine & 3-Hydroxybenzaldehyde & Phenol & Mannoside $^{\mathrm{b}}$ & Trihydroxybenzene \\
\hline 0 & $2.179 \pm 0.023$ & $1.850 \pm 0.039$ & $4.7 \pm 0.12$ & $4.598 \pm 0.084$ & $2.174 \pm 0.017$ & $9.224 \pm 0.047$ \\
\hline 0.027 & $2.301 \pm 0.015$ & $1.996 \pm 0.029$ & $5.8 \pm 0.12$ & $5.576 \pm 0.089$ & $2.313 \pm 0.032$ & $11.750 \pm 0.163$ \\
\hline 0.053 & $2.459 \pm 0.031$ & $2.090 \pm 0.023$ & $6.5 \pm 0.11$ & $6.4 \pm 0.11$ & $2.526 \pm 0.044$ & $13.602 \pm 0.167$ \\
\hline 0.107 & $2.589 \pm 0.033$ & $2.265 \pm 0.036$ & $7.4 \pm 0.12$ & $7.4 \pm 0.16$ & $2.649 \pm 0.026$ & $15.539 \pm 0.358$ \\
\hline 0.215 & $2.769 \pm 0.037$ & $2.381 \pm 0.043$ & $8.4 \pm 0.13$ & $8.0 \pm 0.16$ & $2.871 \pm 0.052$ & $15.301 \pm 0.364$ \\
\hline 0.543 & $2.868 \pm 0.065$ & $2.218 \pm 0.043$ & $8.8 \pm 0.21$ & $8.694 \pm 0.095$ & $3.037 \pm 0.058$ & $14.903 \pm 0.129$ \\
\hline 1.109 & $2.869 \pm 0.044$ & $1.863 \pm 0.034$ & $9.3 \pm 0.28$ & $10.1 \pm 0.34$ & $3.139 \pm 0.044$ & $14.637 \pm 0.283$ \\
\hline 1.936 & $2.851 \pm 0.039$ & $1.482 \pm 0.034$ & $10.9 \pm 0.33$ & $13.1 \pm 0.37$ & $3.285 \pm 0.067$ & $16.820 \pm 0.334$ \\
\hline $\mathrm{NaSCN}(\mathrm{M})$ & Adenosine & Salicin & p-Nitroanisole & Guanosine & 4-Aminophenol & 4-Hydroxyacetanilide \\
\hline 0 & $2.634 \pm 0.017$ & $1.918 \pm 0.070$ & $4.697 \pm 0.062$ & $1.673 \pm 0.008$ & $3.038 \pm 0.049$ & $5.353 \pm 0.045$ \\
\hline 0.027 & $2.762 \pm 0.027$ & $1.986 \pm 0.026$ & $5.560 \pm 0.096$ & $1.707 \pm 0.029$ & $3.469 \pm 0.059$ & $6.5 \pm 0.12$ \\
\hline 0.053 & $2.893 \pm 0.029$ & $2.072 \pm 0.030$ & $6.475 \pm 0.097$ & $1.731 \pm 0.021$ & $3.698 \pm 0.045$ & $7.4 \pm 0.12$ \\
\hline 0.107 & $3.074 \pm 0.044$ & $2.175 \pm 0.048$ & $7.7 \pm 0.13$ & $1.739 \pm 0.020$ & $3.983 \pm 0.081$ & $8.5 \pm 0.15$ \\
\hline 0.215 & $3.232 \pm 0.042$ & $2.262 \pm 0.037$ & $8.7 \pm 0.22$ & $1.732 \pm 0.028$ & $4.319 \pm 0.060$ & $9.4 \pm 0.16$ \\
\hline 0.543 & $2.916 \pm 0.034$ & $2.460 \pm 0.049$ & $9.6 \pm 0.22$ & $1.657 \pm 0.023$ & $4.566 \pm 0.047$ & $9.5 \pm 0.13$ \\
\hline 1.109 & $2.630 \pm 0.024$ & $2.606 \pm 0.050$ & $10.4 \pm 0.33$ & $1.529 \pm 0.020$ & $4.830 \pm 0.088$ & $9.9 \pm 0.19$ \\
\hline 1.936 & $2.197 \pm 0.050$ & $2.644 \pm 0.033$ & $11.8 \pm 0.38$ & $1.322 \pm 0.062$ & $5.1 \pm 0.11$ & $11.8 \pm 0.42$ \\
\hline
\end{tabular}

a p-Nitrophenyl- $\alpha$-D-glucopyranoside.

b p-Nitrophenyl- $\alpha$-D-mannopyranoside. 
Table 4

Partition coefficients of nonionic compounds in PEG-8000- $\mathrm{Na}_{2} \mathrm{SO}_{4}$ aqueous two-phase system with different concentrations of $\mathrm{NaH}_{2} \mathrm{PO}_{4}$ additive.

\begin{tabular}{|c|c|c|c|c|c|c|}
\hline $\mathrm{NaH}_{2} \mathrm{PO}_{4}(\mathrm{M})$ & Glucoside $^{a}$ & Caffeine & 3-Hydroxybenzaldehyde & Phenol & Mannoside ${ }^{b}$ & 4-Hydroxyacetanilide \\
\hline 0 & $2.179 \pm 0.023$ & $1.850 \pm 0.039$ & $4.7 \pm 0.12$ & $4.598 \pm 0.084$ & $2.174 \pm 0.017$ & $5.353 \pm 0.045$ \\
\hline 0.027 & $2.255 \pm 0.048$ & $1.888 \pm 0.019$ & $5.117 \pm 0.070$ & $5.2 \pm 0.17$ & $2.244 \pm 0.036$ & $5.645 \pm 0.033$ \\
\hline 0.054 & $2.384 \pm 0.045$ & $1.978 \pm 0.032$ & $5.587 \pm 0.081$ & $5.5 \pm 0.18$ & $2.353 \pm 0.031$ & $6.174 \pm 0.074$ \\
\hline 0.108 & $2.542 \pm 0.042$ & $2.125 \pm 0.034$ & $6.347 \pm 0.057$ & $6.2 \pm 0.18$ & $2.553 \pm 0.047$ & $7.36 \pm 0.12$ \\
\hline 0.217 & $3.072 \pm 0.052$ & $2.382 \pm 0.033$ & $7.929 \pm 0.097$ & $8.1 \pm 0.14$ & $3.114 \pm 0.052$ & $10.12 \pm 0.22$ \\
\hline 0.556 & $4.583 \pm 0.067$ & $3.222 \pm 0.026$ & $14.7 \pm 0.31$ & $15.3 \pm 0.4$ & $4.723 \pm 0.093$ & $17.80 \pm 0.27$ \\
\hline 1.160 & $8.8 \pm 0.17$ & $5.2 \pm 0.07$ & $33.6 \pm 0.8$ & $37 \pm 1.9$ & $9.32 \pm 0.19$ & $42 \pm 1.7$ \\
\hline 1.751 & $18.8 \pm 0.68$ & $8.7 \pm 0.28$ & $74 \pm 3$ & $78 \pm 4$ & $18.85 \pm 0.67$ & $76 \pm 5$ \\
\hline $\mathrm{NaH}_{2} \mathrm{PO}_{4}(\mathrm{M})$ & & Adenosine & Salicin & \multicolumn{2}{|c|}{ p-Nitroanisole } & Guanosine \\
\hline 0 & & $2.634 \pm 0.017$ & $1.918 \pm 0.070$ & \multicolumn{2}{|c|}{$4.697 \pm 0.062$} & $1.673 \pm 0.008$ \\
\hline 0.027 & & $2.562 \pm 0.072$ & $2.015 \pm 0.040$ & \multicolumn{2}{|c|}{$5.086 \pm 0.084$} & $1.711 \pm 0.035$ \\
\hline 0.054 & & $2.622 \pm 0.062$ & $2.074 \pm 0.043$ & \multicolumn{2}{|c|}{$5.753 \pm 0.077$} & $1.744 \pm 0.037$ \\
\hline 0.108 & & $2.631 \pm 0.048$ & $2.256 \pm 0.049$ & \multicolumn{2}{|c|}{$6.7 \pm 0.11$} & $1.804 \pm 0.024$ \\
\hline 0.217 & & $2.701 \pm 0.064$ & $2.573 \pm 0.070$ & \multicolumn{2}{|c|}{$9.3 \pm 0.26$} & $2.062 \pm 0.044$ \\
\hline 0.556 & & $2.529 \pm 0.042$ & $3.6 \pm 0.11$ & \multicolumn{2}{|c|}{$20.0 \pm 0.38$} & $2.323 \pm 0.028$ \\
\hline 1.160 & & $2.182 \pm 0.029$ & $6.2 \pm 0.11$ & \multicolumn{2}{|c|}{$69 \pm 4$} & $2.877 \pm 0.050$ \\
\hline 1.751 & & $2.135 \pm 0.032$ & $10.3 \pm 0.42$ & & & $3.492 \pm 0.063$ \\
\hline
\end{tabular}

a p-Nitrophenyl- $\alpha$-D-glucopyranoside.

b p-Nitrophenyl- $\alpha$-D-mannopyranoside.

not studied in the presence of the $\mathrm{NaH}_{2} \mathrm{PO}_{4}$ additive due to arisen analytical challenges.

\section{Discussion}

Analysis of the partition coefficients of the compounds examined in the presence of different salt additives listed in Tables 1-4 indicates that the variability in salt additive effect is not limited to the salt type but appears to also be compound specific. This observation is unexpected, given the nonionic nature of the compounds used in the experiments. As an illustration of the above conclusion, the ratio of the partition coefficient of a solute at the highest salt additive concentration to that in the original ATPS without any salt additive is plotted for several compounds, against the type of salt additive in Fig. 10. Lines connecting the experimental points are added for eye-guidance only.

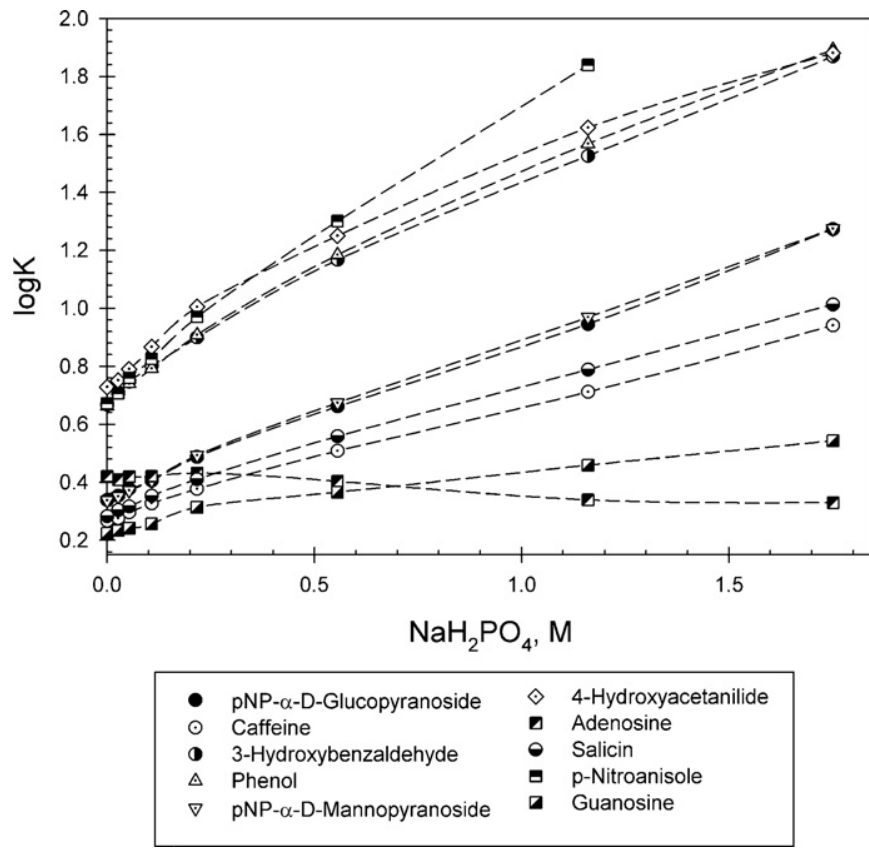

Fig. 9. Concentration effects of $\mathrm{NaH}_{2} \mathrm{PO}_{4}$ additive on the logarithms of partition coefficients of nonionic compounds in aqueous PEG-8000- $\mathrm{Na}_{2} \mathrm{SO}_{4}$ two-phase system. Lines connecting the experimental points are added for eye-guidance only.
It was shown previously [15] that the so-called Collander relationship described by Eq. (1) holds for both nonionic and ionized compounds in ATPS formed by different combinations of certain two nonionic polymers at a fixed ionic composition. It was also reported [21] that the relationship is valid for partitioning of nonionic and ionized compounds in UCON-NaH $\mathrm{H}_{2} \mathrm{PO}_{4}$ and UCON$\mathrm{K}_{2} \mathrm{HPO}_{4}$ systems. Therefore, if the only difference between the ATPS with various concentrations of salt additives is the different polymer and salt compositions of the coexisting phases, it seems reasonable for nonionic compounds to expect this relationship to hold:

$\log K_{j i}=a_{j i} \times \log K_{o}+b_{j i}$

where $K_{0}$ is the nonionic solute partition coefficient in the PEG- $\mathrm{Na}_{2} \mathrm{SO}_{4}$ ATPS without salt additives (used as a reference ATPS); $K_{j i}$ is the same solute partition coefficient in the ATPS with a $j$-th salt additive at a $i$-th concentration; $a_{j i}$ and $b_{j i}$ are constants, the values of which depend upon the particular composition of the $j i$-th and $o$-th two-phase systems under comparison.

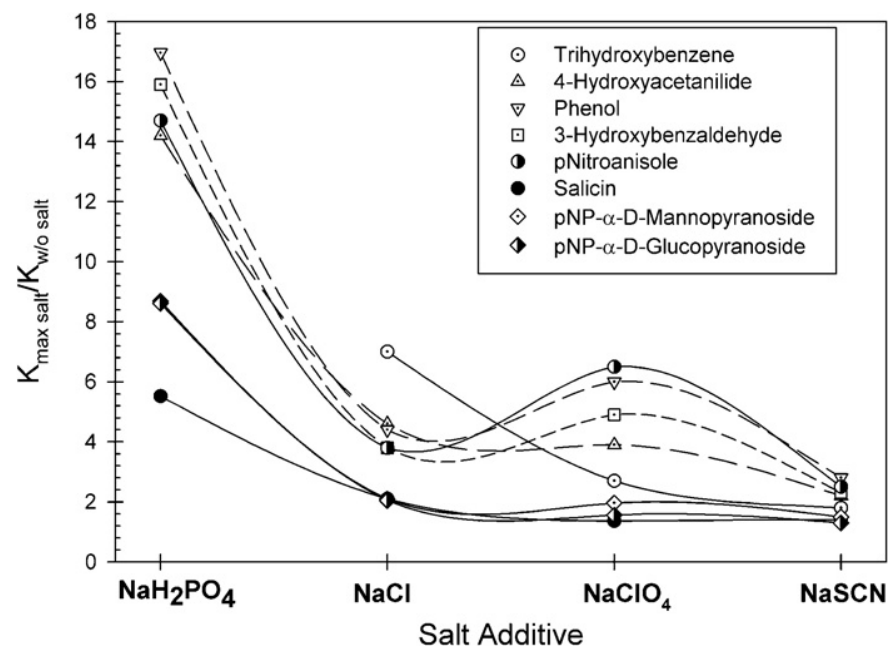

Fig. 10. The ratio of the partition coefficient of a nonionic compound in aqueous PEG-8000- $\mathrm{Na}_{2} \mathrm{SO}_{4}$ two-phase system with maximum salt additive concentration used to that in the same system without salt additive versus type of salt additive. Salt additives are placed in the order representative of the salt effect on the water structure (from the structure-enhancing to structure-breaking). Lines connecting the experimental points are added for eye-guidance only. 


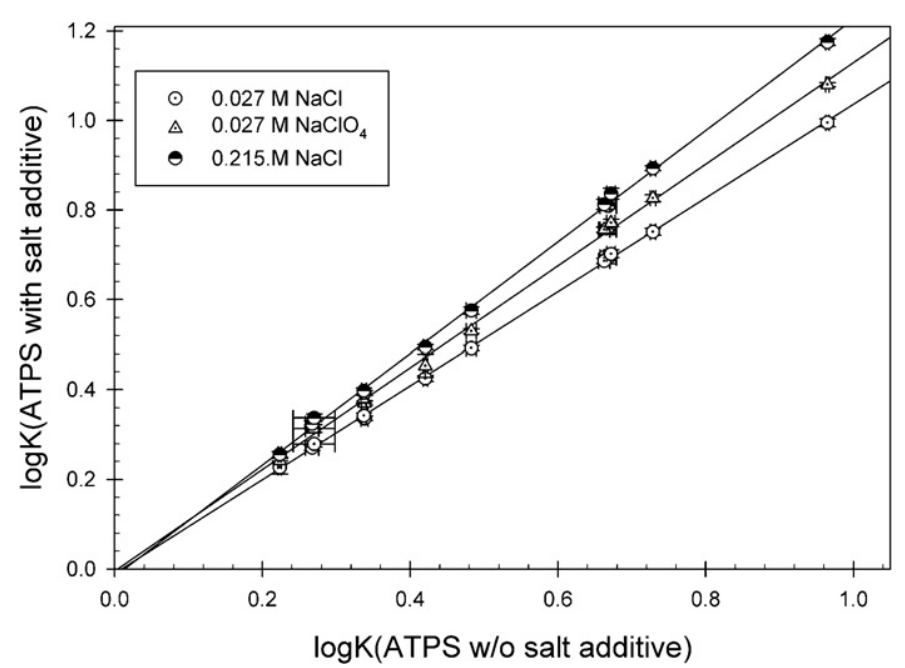

Fig. 11. Logarithms of partition coefficients for nonionic compounds in aqueous PEG-8000- $\mathrm{Na}_{2} \mathrm{SO}_{4}$ two-phase system with indicated concentration of salt additive versus logarithms of partition coefficients for nonionic compounds in aqueous PEG$8000-\mathrm{Na}_{2} \mathrm{SO}_{4}$ two-phase system without salt additive.

It should be noted that the relationship described by Eq. (2) was established for comparison of partition coefficients of solutes in different organic solvent-water systems. It was found to be valid for solutes of the same chemical nature, as it holds only if the relative intensities of all the solvent-solute interactions in the coexisting phases are changed similarly in the systems under comparison. Data reported in the literature $[5,16,22,23]$ on the relative hydrophobicity of various ATPS measured by the free energy of transfer of a methylene group between the coexisting phases show that the relative hydrophobicity of ATPS formed by PEG and salt are close to that typical for organic solvent-water systems. It is likely that in ATPS with high salt additive concentrations some specific solute-solvent interactions may occur for certain solutes under study as the result of ion-dipole, ion-induced dipole, and dipole-induced dipole interactions, for example. Occurrence of specific solute-solvent interactions in one of the ATPS under comparison for some of the solutes only would result in breaking the Collander relationship.

Typical examples of the observed relationships described by Eq. (2) are presented in Fig. 11. Analysis of the data listed in Tables 1-4 shows that for all the ATPS with $\mathrm{NaCl}$ additives Eq. (2) is valid for nonionic compounds up to $0.215 \mathrm{M} \mathrm{NaCl}$ content. The PEG- $\mathrm{Na}_{2} \mathrm{SO}_{4}$ ATPS with the up to $0.215 \mathrm{M} \mathrm{NaCl}$ concentration may be viewed as similar to the ATPS without $\mathrm{NaCl}$ for partitioning of nonionic compounds. All the ATPS with each of the salt additive used at the additive concentration of $0.027 \mathrm{M}$ also may be viewed as similar to each other, all obeying Eq. (1). Collander equation is valid also for the compounds examined in the ATPS with additives of NaSCN and $\mathrm{NaClO}_{4}$ at the concentrations up to $0.215 \mathrm{M}$. The observed similarity between these ATPS might be explained by the similar effects of these two salts on the water structure [24].

The coefficients $a_{j i}$ and $b_{j i}$ values are listed in Table 5. The relationship described by Eq. (2) in each case was only judged to be valid if no more than a single data point deviated from the correlation by more than $5 \%$. That means that the specific effects of the $\mathrm{NaH}_{2} \mathrm{PO}_{4}$ additive on the partitioning of nonionic compounds examined relative to the ATPS without salt additive is displayed at the concentrations of $0.027 \mathrm{M}$ and above. Specific effects of the additive relative to the ATPS with $\mathrm{NaCl}$ additive are displayed for $\mathrm{NaH}_{2} \mathrm{PO}_{4}, \mathrm{NaClO}_{4}$ and $\mathrm{NaSCN}$ at the concentrations of $0.053 \mathrm{M}$ and above, while different effects of the $\mathrm{NaSCN}$ and $\mathrm{NaClO}_{4}$ additives on the nonionic solute partitioning relative to each other are displayed at the concentrations of ca. $0.54 \mathrm{M}$ and above. The observed similarity in the partitioning of nonionic solutes in the PEG- $\mathrm{Na}_{2} \mathrm{SO}_{4}$ ATPS with or without salt additives implies that the differences could be attributed to changes in the compositions of the coexisting phases resulting from the presence of a given salt additive while maintaining the key properties of the phases important for their partitioning capacity.

It should be noticed that the partition coefficients for the studied solutes in the ATPS with $\mathrm{NaClO}_{4}$ and $\mathrm{NaSCN}$ additives at relatively high concentrations differ from each other more significantly than in the ATPS with low additive content. As an example, the partition coefficients are essentially identical for the p-NP- $\alpha$ D-glucopyranoside and $\mathrm{p}-\mathrm{NP}-\alpha-\mathrm{D}$-mannopyranoside in the ATPS without salt additive and remain extremely close in the presence of $\mathrm{NaCl}$ (Table 1 ) but are clearly different in the presence of $0.5-1.8 \mathrm{M} \mathrm{NaClO}_{4}$ (see in Table 2) and in the presence of 1.1-1.9 M NaSCN (see in Table 3). The partition coefficients for phenol and 3-hydroxybenzaldehyde are clearly different in the ATPS without salt additives, are relatively close in the presence of the salt additives and are significantly different at high concentrations of the additives.

All the nonionic compounds examined here may be divided into two groups according to their relative lipophilicity:

Table 5

Coefficients of the Collander equation $\left(\log K_{X}=a_{j i} \times \log K_{o}+b_{j i}\right.$; Eq. (1)).

\begin{tabular}{|c|c|c|c|c|c|c|c|c|}
\hline$X^{\mathrm{a}}$ & {$[\text { Salt }]^{\mathrm{b}}(\mathrm{M})$} & Reference $^{c}$ & $b_{j i}$ & $a_{j i}$ & $r^{2}$ & $F$ & SD & N/Outlier \\
\hline $\mathrm{NaClO}_{4}$ & 0.027 & No additive & $-0.004 \pm 0.009$ & $1.134 \pm 0.015$ & 0.9981 & 5381.7 & 0.0119 & 12/None \\
\hline NaSCN & 0.027 & No additive & $-0.015 \pm 0.008$ & $1.135 \pm 0.015$ & 0.9983 & 5977.06 & 0.0113 & 12/None \\
\hline $\mathrm{NaCl}$ & 0.027 & No additive & $-0.009 \pm 0.004$ & $1.046 \pm 0.007$ & 0.9996 & $22,805.0$ & 0.0053 & $12 /$ None \\
\hline $\mathrm{NaCl}$ & 0.053 & No additive & $-0.013 \pm 0.005$ & $1.093 \pm 0.008$ & 0.9994 & $16,979.6$ & 0.0065 & $12 /$ None \\
\hline $\mathrm{NaCl}$ & 0.107 & No additive & $-0.018 \pm 0.006$ & $1.157 \pm 0.011$ & 0.9991 & $11,728.5$ & 0.0082 & $12 /$ Salicin \\
\hline $\mathrm{NaCl}$ & 0.215 & No additive & $-0.016 \pm 0.008$ & $1.242 \pm 0.014$ & 0.9986 & 7372.7 & 0.0112 & $12 /$ Salicin \\
\hline $\mathrm{NaClO}_{4}$ & 0.027 & $\mathrm{NaCl}$ & $0.006 \pm 0.006$ & $1.085 \pm 0.011$ & 0.9991 & $10,622.5$ & 0.0085 & $12 /$ None \\
\hline $\mathrm{NaSCN}$ & 0.027 & $\mathrm{NaCl}$ & $-0.005 \pm 0.007$ & $1.085 \pm 0.011$ & 0.9988 & 8250.2 & 0.0096 & $12 /$ None \\
\hline $\mathrm{NaSCN}$ & 0.027 & $\mathrm{NaClO}_{4}$ & $-0.010 \pm 0.007$ & $1.000 \pm 0.011$ & 0.9987 & 7679.1 & 0.010 & $12 /$ None \\
\hline $\mathrm{NaH}_{2} \mathrm{PO}_{4}$ & 0.027 & $\mathrm{NaCl}$ & $0.009 \pm 0.011$ & $1.001 \pm 0.022$ & 0.9962 & 2082.5 & 0.014 & 10/Salicin \\
\hline $\mathrm{NaH}_{2} \mathrm{PO}_{4}$ & 0.027 & $\mathrm{NaSCN}$ & $0.016 \pm 0.009$ & $0.918 \pm 0.016$ & 0.9975 & 3151.8 & 0.0113 & 10/Caffeine \\
\hline $\mathrm{NaH}_{2} \mathrm{PO}_{4}$ & 0.027 & $\mathrm{NaClO}_{4}$ & $0.005 \pm 0.010$ & $0.918 \pm 0.018$ & 0.9969 & 2613.4 & 0.012 & 10/Caffeine \\
\hline $\mathrm{NaSCN}$ & $0.053(4)$ & $\mathrm{NaClO}_{4}$ & $-0.007 \pm 0.008$ & $0.992 \pm 0.013$ & 0.9984 & 6179.7 & 0.012 & $12 /$ None \\
\hline $\mathrm{NaSCN}$ & 0.107 & $\mathrm{NaClO}_{4}$ & $-0.0003 \pm 0.008$ & $0.973 \pm 0.011$ & 0.9988 & 8517.1 & 0.0109 & 12/None \\
\hline $\mathrm{NaSCN}$ & 0.215 & $\mathrm{NaClO}_{4}$ & $0.010 \pm 0.011$ & $0.942 \pm 0.015$ & 0.9975 & 4033.6 & 0.016 & 12/Caffeine \\
\hline
\end{tabular}

a Salt additive present in the ATPS compared to the reference ATPS.

b Concentration of the salt additive present in the ATPS compared to the reference ATPS.

c Salt additive present in the ATPS used as a reference.

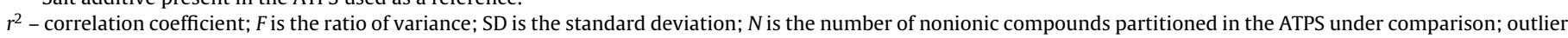
- compound for which the $\log K$ values in the compared ATPS deviated from the relationship described by Eq. (1) by more than $5 \%$. 
Table 6

Lipophilicity $(\log P)$ and molecular polarizability values for nonionic compounds.

\begin{tabular}{lcc}
\hline Compound & $\begin{array}{l}\text { Lipophilicity } \\
(\log P)^{\mathrm{a}}\end{array}$ & $\begin{array}{l}\text { Molecular } \\
\text { polarizability } \\
10^{-24}\left(\mathrm{~cm}^{3}\right)\end{array}$ \\
\hline p-Nitroanisole & 2.03 & $15.64 \pm 0.5$ \\
Phenol & 1.46 & $11.15 \pm 0.5$ \\
3-Hydroxybenzaldehyde & 1.38 & $13.83 \pm 0.5$ \\
4-Hydroxyacetanilide & 0.51 & $16.81 \pm 0.5$ \\
Trihydroxybenzene & 0.16 & $12.64 \pm 0.5$ \\
p-Aminophenol & 0.04 & $12.83 \pm 0.5$ \\
Caffeine & -0.07 & $19.97 \pm 0.5$ \\
p-Nitrophenyl-mannopyranoside & -0.46 & $27.15 \pm 0.5$ \\
p-Nitrophenyl-glucopyranoside & -0.46 & $27.15 \pm 0.5$ \\
Adenosine & -1.06 & $23.76 \pm 0.5$ \\
Salicin & -1.22 & $27.12 \pm 0.5$ \\
Guanosine & -1.89 & $24.1 \pm 0.5$ \\
\hline
\end{tabular}

a $\log P$ values from Hansch, C., Leo, A., Hoekman, D., Exploring QSAR: Hydrophobic, Electronic, and Steric Constants, American Chemical Society, Washington, DC, 1995.

b Molecular polarizability values calculated with ACD/ChemSketch v.11.01 software.

one group includes relatively lipophilic compounds (trihydroxybenzene, phenol, p-nitroanisole, 4-hydroxyacetanilide, 3-hydroxybenzaldehyde, and p-aminophenol are characterized by $\log P>0$ ) and the other group includes more hydrophilic compounds with $\log P<0$ (caffeine, pNP-glucopyranoside, pNPmannopyranoside, adenosine, salicin, and guanosine). Molecular polarizabilities for the compounds divided in these two groups are also clearly different being significantly higher for more hydrophilic compounds. The experimental $\log P$ and calculated molecular polarizability values are presented in Table 6 . Lipophilicity was used as a measure of the solute preference for a non-aqueous media, and polarizability as that of the dipole response to the electrostatic field present due to the high ion concentrations. It follows from examination of the partition coefficients and the above properties of the compounds studied that the molecular polarizability and lipophilicity are not the only factors governing their partition behavior.

The observed relationships between salt additive concentration and partition coefficients of nonionic compounds are similar to typical salting-out and salting-in effects. It must be stressed that the similarity is qualitative only and that in contrast to salting-out (or salting-in) phenomena in this case the observed relationship is actually a set of discrete points, each specific for a particular twophase system formed in the presence of a given concentration of the salt additive. Changes in the ratio of the volumes of the coexisting phases illustrated in Fig. 1 clearly indicate that different systems are formed at different concentrations of each salt additive. In contrast to the salting-in or salting-out effect when the salt concentration effect (increased ionic charge density effect) on the solubility or other properties of a solute in aqueous solution likely due to amplification (decrease) of the hydrophobic interactions between solutes [25], addition of a given salt additive to a PEG-sulfate ATPS may lead to changes in the polymer and salt compositions of the two coexisting phases resulting in changes in the solvent features of aqueous media in the two phases. These factors are interrelated and cannot be considered separately.

Caffeine, adenosine, and guanosine all belong to the class of purine derivatives and demonstrate partition behavior in ATPS with high $\mathrm{NaClO}_{4}$ and NaSCN concentrations clearly different from those of other compounds we studied. Solubility of adenosine and caffeine in water is known to increase with increased concentrations of $\mathrm{NaClO}_{4}$ and $\mathrm{NaSCN}$ [26-28]. It is reasonable to assume that guanosine would display similar behavior. Therefore it is possible to suggest that partitioning of these compounds into salt-rich phase at high $\mathrm{NaClO}_{4}$ and $\mathrm{NaSCN}$ concentrations is related to their increased solubility in the aqueous media in this phase. It should be mentioned here that the concentrations of compounds under study were always sufficiently low and no precipitation of any solute was detected.

It was established previously in two-polymer ATPS that the Collander relationship does not hold for the partition coefficients of different compounds in systems formed by certain polymers. For example, such a relationship does not hold for partition coefficients in dextran-PEG and dextran-Ficoll ATPS [15]. The reason appears to be that the Collander relationship (Eq. (1)) is based on the oversimplified concept of mechanism of partitioning [29]. It implies that there are just two additive factors driving distribution of a solute between the coexisting phases, namely, the difference between the relative hydrophobicity of the phases and the difference between the solute-solvent polar interactions in the two phases. It was shown $[22,23,29]$ that the partition coefficient of solute in both PEG-salt and two-polymer ATPS is described better as a sum of intensities of different solute-solvent interactions within the framework of the so-called Linear Solvation Energy Relationship (LSER) model developed by Abraham [30-34]. Future studies will investigate whether this approach would be useful for describing the mechanisms surrounding the effects of salt additives on partitioning of solutes in PEG-salt ATPS.

The results obtained in this study is the first experimental evidence that salt additives affect partitioning of nonionic compounds in aqueous PEG-salt two-phase systems. It seems pretty obvious from the results obtained so far that the partition behavior of a nonionic solute in the polymer-salt ATPS cannot be explained based on considerations of differences between the compositions of the coexisting phases alone due to the current lack of understanding of both polymer and salt effects on the solvent features of aqueous media in the phases. We are currently working on characterization of solvent features of the aqueous media in the coexisting phases of the ATPS used in the present work. We also plan to examine the effects of salt additives on partitioning of small ionized organic compounds, in order to gain better insight into the mechanism of solute partitioning in PEG-salt ATPS.

\section{Acknowledgement}

Luisa A. Ferreira acknowledges the financial support (SFRH/BPD/47607/2008) from Fundação para a Ciência e a Tecnologia (Lisboa, Portugal).

\section{References}

[1] H. Hustedt, K.H. Kroner, M.R. Kula, in: Walter, D.E. Brooks, D. Fisher (Eds.), Partitioning in Aqueous Two-phase Systems: Theory, Methods, Use, and Applications to Biotechnology, Academic Press, Orlando, FL, 1985, p. 529.

[2] B.A. Andrews, S. Nielsen, J.A. Asenjo, Bioseparation 6 (1996) 303.

[3] P.A.J. Rosa, A.M. Azevedo, S. Sommerfeld, M. Mutter, M.R. Aires-Barros, W. Backer, J. Biotechnol. 139 (2009) 306.

[4] S.A. Oelmeier, F. Dismer, J. Hubbuch, Biotechnol. Bioeng. 108 (2011) 69.

[5] B.Y. Zaslavsky, Aqueous Two-phase Partitioning: Physical Chemistry and Bioanalytical Applications, Marcel Dekker, New York, 1994.

[6] B.A. Andrews, A.S. Schmidt, J.A. Asenjo, Biotechnol. Bioeng. 90 (2005) 380.

[7] A.M. Azevedo, A.G. Gomes, P.A.J. Rosa, I.F. Ferreira, A.M.M.O. Pisco, M.R. AiresBarros, Sep. Purif. Technol. 65 (2009) 14.

[8] R.L. de Spuza, J.M.P. Barbosa, G.M. Zanin, W.N. Lobao, C.M.F. Soares, A.S. Lima, Appl. Biochem. Biotechnol. 494 (2010) 288

[9] F. Leuchau, T.C. Ling, A. Lyddiatt, Sep. Purif. Technol. 68 (2009) 114.

[10] G. Tubio, G.A. Pico, B.B. Nerli, J. Chromatogr. B 877 (2008) 115.

[11] D.M. Pericin, S.Z. Madarev-Popovic, L.M. Radulovic-Popovic, Biotechnol. Lett. 31 (2009) 43.

[12] M.G. Bertoluzzo, R. Rigatuso, B. Farruggia, B. Nerli, G. Pico, Colloids Surf. B: Biointerf. 59 (2007) 134.

[13] B. Farruggia, R. Rigatuso, L. Capezio, V. Diez, G. Pico, J. Chromatogr. B 809 (2004) 301.

[14] C.K. Su, B.H. Chiang, Process Biochem. 41 (2006) 257.

[15] Y. Xu, J. Lu, D.Q. Li, Prep. Biochem. Biotechnol. 31 (2001) 23.

[16] A. Kaul, in: R. Hatti-Kaul (Ed.), Aqueous Two-phase Systems. Methods and Protocols, Humana Press, Totowa, NJ, 2000, p. 11.

[17] L.A. Ferreira, J.A. Teixeira, J. Chem. Eng. Data 56 (2011) 133. 
[18] J. Merchuk, B. Andrews, J. Asenjo, J. Chromatogr. B 711 (1998) 285.

[19] E.V.C. Cunha, M. Aznar, J. Chem. Eng. Data 54 (2009) 3242.

[20] O. Rodriguez, S.C. Silverio, P.P. Madeira, J.A. Teixeira, E.A. Macedo, Ind. Eng. Chem. Res. 46 (2007) 8199.

[21] P.P. Madeira, J.A. Teixeira, E.A. Macedo, L.M. Mikheeva, B.Y. Zaslavsky, J. Chromatogr. A 1190 (2008) 39.

[22] S.C. Silverio, O. Rodriguez, J.A. Teixeira, E.A. Macedo, Fluid Phase Equilib. 296 (2010) 173

[23] H.D. Willauer, J.G. Huddleston, R.D. Rogers, Ind. Eng. Chem. Res. 41 (2002) 2591

[24] M.L. Moody, H.D. Willauer, S.T. Griffin, J.G. Huddleston, R.D. Rogers, Ind. Eng Chem. Res. 44 (2005) 3749.

[25] Y. Marcus, Pure Appl. Chem. 82 (2010) 1889.
[26] R. Zangi, J. Phys. Chem. B 114 (2010) 643.

[27] A. Al-Maaieh, D.R. Flanagan, J. Pharm. Sci. 91 (2002) 1000

[28] Y. Hatefi, W.G. Hanstein, Proc. Natl. Acad. Sci. U.S.A. 62 (1969) 1129

[29] D.R. Robinson, M.E. Grant, J. Biol. Chem. 241 (1966) 4030.

[30] P.P. Madeira, C.A. Reis, A.E. Rodrigues, L.M. Mikheeva, B.Y. Zaslavsky, J. Phys. Chem. B 114 (2010) 457

[31] M.H. Abraham, Chem. Soc. Rev. 22 (1993) 73.

[32] M.H. Abraham, C.M. Du, J.A. Platts, J. Org. Chem. 65 (2000) 7114.

[33] M.H. Abraham, A.J.M. Al-Hussaini, J. Environ. Monit. 3 (2001) 377.

[34] A.M. Zissimos, M.H. Abraham, M.C. Barker, K.J. Box, K.Y. Tam, J. Chem. Soc., Perkin Trans. 2 (2002) 470. 